\title{
Toprak sıcaklığının ısı miktarına bağlı olarak değişiminin matematiksel modellenmesi
}

\section{Mathematical modeling of soil temperature change depending on heat amount}

\author{
İmanverdi EKBERLi ${ }^{1 *}$, Coşkun GÜLSER ${ }^{1}$ (D)
}

${ }^{1}$ Ondokuz Mayıs Üniversitesi Ziraat Fakültesi, Toprak Bilimi ve Bitki Besleme Bölümü, Samsun, Türkiye

\section{To cite this article:}

Ekberli, i. \& Gülser, C. (2020). Toprak sıcaklığının ısı miktarına bağlı olarak değişiminin matematiksel modellenmesi. Harran Tarım ve Gıda Bilimleri Dergisi, 24(2): 229-240.

DOI: 10.29050/harranziraat.638162

Address for Correspondence: Imanverdi EKBERLi e-mail:

iman@omu.edu.tr

Received Date:

25.10.2019

Accepted Date:

15.05.2020

(C) Copyright 2018 by Harran University Faculty of Agriculture. Available on-line at www.dergipark.gov.tr/harranziraat

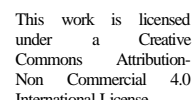

öz

Toprak katmanlarındaki ısı miktarının değişimi, toprağın termo-fiziksel özellikleri, toprak mikro iklimi, toprak oluşum süreçleri vb. üzerinde önemli bir etkiye sahiptir. Bu çalışmada, toprak profilindeki katmanların anlık soğuması durumunda toprağın bir boyutlu ısı iletkenlik denklemi benzerlik teorisine göre incelenmiştir. Çözüm, hata ve tamamlayıcı hata fonksiyonları kullanılarak basit bir şekilde ifade edilmiştir. Toprak katmanının soğuma sürecinde, toprak derinliği boyunca sıcaklığın zamana göre değişimi, toprak derinliği ve ısı miktarının bir fonksiyonu olarak teorik bir ifade ile gösterilmiştir. Araştırma toprağının gravimetrik ISI kapasitesi $950.404 \mathrm{~J} \mathrm{~kg}^{-1}{ }^{\circ} \mathrm{C}^{-1}$ olarak saptanmıştır. Araştırma dönemlerinde toprağın hacimsel ISI kapasitesi ve ISI miktarı sırasıyla $(2.324-2.654) \cdot 10^{6} \mathrm{~J} \mathrm{~m}^{-3}{ }^{\circ} \mathrm{C}^{-1}$ ve $1.027 \cdot 10^{6}-3.227 \cdot 10^{7} \mathrm{~J} \mathrm{~m}^{-2}$ aralığında belirlenmiştir. Isı miktarının sabit olması durumunda, toprağın 0-10 $\mathrm{cm}$ katmanında 10 saat boyunca kaybedilen ISı işleminden sonra toprak sıcaklığı ortalama \%49.20 azalmaktadır. Toprak profilinin alt katmanlarında ise sıcaklı̆ın azalması düşük düzeyde gerçekleşmektedir. Azalma süreci aynı zamanda toprağın gravimetrik ısı kapasitesine, hacimsel ısı kapasitesinin ve ısısal yayınım katsayısının değişimine de önemli derecede bağlı olmaktadır.

Anahtar Kelimeler: Toprak sıcaklığı, Isı miktarı, Benzerlik teorisi, Isı kapasitesi, Toprak derinliği

\section{ABSTRACT}

Change in the amount of heat in soil layers has a significant effect on thermo-physical properties of soil, soil microclimate, soil formation processes and etc. In this study, one dimensional thermal conductivity equation of soil is investigated according to similarity theory in case of instant cooling of soil layer. The solution is simply expressed using the error and complementary error functions. During the cooling process of the soil layer, the change in temperature of soil depth with respect to time is shown with a theoretical expression as a function of soil depth and heat amount. The gravimetric heat capacity of the research soil was determined as $950.404 \mathrm{~J} \mathrm{~kg}^{-1}{ }^{\circ} \mathrm{C}^{-1}$. Volumetric heat capacity and heat quantity of the soil were determined in the range of $2.324 \cdot 10^{6}-2.654 \cdot 10^{6} \mathrm{~J} \mathrm{~m}^{-3}{ }^{\circ} \mathrm{C}^{-1}$ and $1.027 \cdot 10^{6}-3.227 \cdot 10^{7} \mathrm{~J} \mathrm{~m}^{-2}$, respectively. The soil temperature decreases by an average of $49.20 \%$ after 10 hours of heat treatment in the $0-10 \mathrm{~cm}$ soil layer in case of constant heat amount. The temperature decrease in the lower layers of the soil occurs at a low level. The reduction process is also significantly dependent on the gravimetric heat capacity, volumetric heat capacity and the coefficient of thermal diffusion of the soil.

Key Words: Soil temperature, Heat quantity, Similarity theory, Heat capacity, Soil depth
Giriş

Toprakta sıcaklık alanının oluşumu sıcaklık değişimine, dolayısıyla toprağın ISı miktarına (ISI enerjisine) önemli düzeyde bağlı olmaktadır. Isı miktarı ise ısı kapasitesinin ve sıcaklık değişiminin fonksiyonudur. Toprak katmanları arasındaki sıcaklık değişimi, toprağın fiziksel ve termofiziksel 
özellikleri ISı miktarını etkilemektedir. Sıcaklık değişiminin toprağın ISı miktarına bağlı olarak teorik belirlenmesi ve pratikte uygulanması ISI iletkenliği denkleminin incelenmesiyle mümkün olmaktadır.

Çevresel ve biyolojik faktörleri (örneğin, güneş radyasyonu, hava ve toprak sıcaklığı, toprak nemi, buharlaşma, bitki gelişimi vb.) kontrol eden ISI bilançosunun parametrelerinin değişimi de, toprak sıcaklığı ve ısı miktarı arasındaki karşılıklı etkiye bağlıdır (Ding ve ark., 2013; Russell ve ark., 2015; Jia ve ark., 2016; Zhang ve ark., 2016; Ma ve ark., 2018; Eshonkulov ve ark., 2019; Kutikoff ve ark., 2019). Toprak-bitki ortamında oluşan toplam ISI miktarı, ISI depolama bileşenlerinden (hava, biyökütle, su, fotosentez ve toprak ısı depolaması) oluşmaktadır. Toprak ISI miktarı ise, etkili ISI depolama bileşeni olan toprak ISı depolamasına bağıı olup, toprak sıcaklığının değişimine bağlıdır. Oncley ve ark. (2007) yaptıkları bir araştırmada, toplam ISI miktarından ayrılan toprak ISI miktarının 10 watt $\mathrm{m}^{-2}$ olduğunu göstermiş, genel olarak ISI depolamasının (ISı miktarının) gün ortasında ve akşamın erken saatlerinde daha fazla meydana geldiğini vurgulamışlardır.

Toprakların enerji ve nem dengesinin ve ısısal özelliklerinin (ısısal yayınım, Isı iletkenliği, hacimsel ISI kapasitesi) değerlendirilmesine ait çalışmaların yapılmasında, toprak sıcaklığının ve değişiminin belirlenmesi gerekmektedir. IsI iletkenliği modelleri bitkisiz (Milly, 1986; Camillo ve ark., 1983; Novak ve Black, 1985; Passerat de Silans ve ark., 1989; Ekberli ve Gülser, 2015; 2016.) ve bitki altındaki (Braud ve ark., 1995; Ekberli ve Sarılar, 2014) topraklarda sıcaklık değerlerinin ve değişiminin belirlenmesine imkan sağlamaktadır. Araştırmanın amacına uygun olarak, toprağın ISı iletkenliği denkleminin çözümünde farklı sınır ve başlangıç koşullarına dayanarak, çeşitli yöntemlerden kullanılmaktadır (Cichota ve ark., 2004; Liu ve ark., 2005; Swain ve ark., 2012; Huang ve ark., 2014; Zhu ve ark., 2014; Ekberli ve ark., 2016; 2017; Oosterkamp ve ark., 2016; Kuznetsov ve ark., 2018). Passerat de Silans ve ark. (1996) tarafından toprağın ısısal yayınımının belirlenmesine ait yapılan bir araştırmada, ISı taşınımı denkleminin çözümünde harmonik, Laplace dönüşümü, düzeltilmiş Laplace dönüşümü ve homojen olmayan toprak sisteminde Lettau yöntemi (Lettau, 1954) uygulanmıştır. Bazı araştırmacılar ise ısı iletkenliği denkleminin çözümünde, bağımsı değişkenlerin sayısını azaltarak denklemin sadeleştirilmesine imkan sağlayan, benzerlik teorisinden yararlanmışlardır (Okoya, 2001; Afify, 2009; Ihsak, 2010; Samanta ve Guha, 2012; Ekberli ve ark., 2015; Xu ve ark., 2015). Bitki altındaki toprakta su ve ISı taşınımının modellenmesine ait bir araştırmada, sonlu elemanlar yöntemi ile toprağın ISI iletkenliği denkleminin çözümü geliştirilmiş, başlangıç ve sınır koşulu olarak sıcaklığın kosinüsoidal değişiminden ve maksimum ve minimum değerlerinden kullanılmıştır (Antonopoulos, 2006). Toprağın temel ISI özelliklerinin (ısısal yayınım, Isı iletkenliği ve Isı akışı) belirlenmesinde kullanılan ISı iletkenliği denkleminin çözümünün elde edilmesinde ise, sınır koşulu olarak toprak yüzeyinde sıcaklığın harmonik değişimini (sinüsoidal ve kosinüsoidal) göz önüne alınmıştır (Evett ve ark., 2012). Temel ISI iletkenliği denkleminin, toprak yüzeyinde ve herhangi bir derinliğindeki sıcaklık değişimleri arasındaki faz değişimini de içeren sınır koşuluna göre irdelenmesine ait bir çalışmada (Gülser ve ark., 2018), sınır koşulu olarak sinüs ve kosinüs fonksiyonlarını içeren matematiksel ifade kullanılmıştır. Toprak ve su değerlendirme aracının ampirik ve fiziksel temelli yöntemlerinden yararlanılarak ılıman bir bölgede toprak sıcaklığının modellenmesine yönelik yapılan bir araştırmada, ısı iletkenliği denkleminin sınır koşullarını belirlemek için ISI bilançosu denkleminden faydalanılmıştır (Qi ve ark., 2019). Toprak sıcaklığının düzenlenmesinde ve tahmin edilmesinde, bitki gelişiminde önemli ısısal parametreler olan sıcaklığın profil boyunca sönme derinliğinin ve gecikme zamanının belirlenmesinde, ISı iletkenliği denkleminin çözümünden elde edilen teorik matematiksel ifadeler kullanılmaktadır (Krarti ve ark., 1995; Gülser ve Ekberli, 2004; Holmes ve ark., 2008; Ekberli ve Sarılar, 2015; Russell ve ark., 2015; Hu ve ark., 2016). 
$\mathrm{Bu}$ çalışmanın amacı, toprağın bir boyutlu ısı iletkenliği denkleminin, benzerlik değişkenine bağı boyutsuz sıcaklık fonksiyonu dahil edilerek, benzerlik teorisine göre ISI miktarına bağlı çözümünün, çözüme etki yapan bazı termofiziksel özelliklerin ve çözümün uygulanabilirliğinin incelenmesidir.

\section{Materyal ve Yöntem}

Toprağın ISı iletkenliği süreci (ISı taşınımı) bu sürecin temel etkileyici faktörü olan toprak sıcaklığının mekana ve zamana göre değişimi sonucunda oluşmaktadır. Toprağın ISI iletkenliğinin belirlenmesinde deneysel ve teorik yöntemlerden kullanılmaktadır.

Isı iletkenliğinin teorik incelenmesi sıcaklığın mekana ( $x, y, z$ uzay koordinatlarına) ve zamana ( $t$ ) göre değişiminin belirlenmesine bağlı olup,

$T=f(x, y, z, t)$

denkleminin yapılmasını gerektirmektedir. Eşitlik (1), toprağın tüm noktalarında ve her bir zaman adımında (aralığında) sıcaklık değerlerinin toplamını gösteren sıcaklık alanının matematiksel ifadesi olmaktadır. Sıcaklığın zamana bağlı olarak değişen değerlerine uygun olarak sabit ve değişken sıcaklık alanı tespit edilmektedir. Sıcaklığın bir koordinatın fonksiyonu olması varsayımı durumunda, bir boyutlu sıcaklık alanı $\left(T=f(x, t) ; \quad \frac{\partial T}{\partial y}=\frac{\partial T}{\partial z}=0\right) \quad$ oluşmakta ve herhangi bir toprak katmanında sıcaklığın zamana göre değişimi bir boyutlu ISI iletkenliği denklemiyle ifade edilmektedir. Isı iletkenliği denklemi, bu çalışmada sıcaklığın toprağın herhangi bir katmanında zamana bağı dağılımının tahmin edilmesi için kullanılacak modelin materyalini oluşturmaktadır. Modelin oluşturulmasında, benzerlik değişkenine bağlı boyutsuz sıcaklık fonksiyonu dahil edilerek, boyutlu fiziksel parametreleri birleştirerek boyutsuz bir biçimde ifade edilmesine olanak sağlayan benzerlik teorisi yöntemi kullanılmıştır.

\section{Bulgular ve Tartışma}

Isı miktarına bağlı olarak toprak sıcaklığının teorik incelenmesi

Toprağın herhangi bir alt katmanlarında ortalama sıcaklığın sabit olması varsayımında, katmanlar arasındaki sıcaklık farkları ısı miktarı oluşturmakta ve oluşan ISI miktarı sıcaklık değişimine etki yapmaktadır. Bu durumda sıcaklık değişiminin nicel olarak değerlendirilmesi için ISI iletkenliği denkleminin uygulanması mümkün olmaktadır.

Toprak yüzeyinde ve alt katmanlarda sıcaklığın değişimi, toprakta ISI taşınımına neden olmaktadır. Toprağın zamana bağlı bir boyutlu ISI iletkenliği süreci, ikinci mertebeden parabolik tipli kısmı türevli diferansiyel denklemle (Eşitlik 2) aşağıdaki gibi ifade edilmekte, toprak ve diğer bilim dallarında geniş düzeyde uygulanmaktadır (Cichota ve ark., 2004; Goldstein, 2010a,b; Evett ve ark., 2012; Ekberli ve Gülser, 2014; van Lopik ve ark., 2015; Chen ve ark., 2016; Liang ve ark., 2017; Thiery ve ark., 2018; Barraza ve ark., 2019; Gülser ve arak., 2019).

$$
\begin{aligned}
& \frac{\partial T}{\partial t}=a \frac{\partial^{2} T}{\partial x^{2}} \quad(0 \leq x<\infty,-\infty<t), \\
& a=\frac{\lambda}{C_{H}}
\end{aligned}
$$

Burada, $T$ - toprak katmanının sıcaklığı $\left({ }^{\circ} \mathrm{C}\right) ; t$ zaman (sn); $a$-ısısal yayınım katsayısı $\left(\mathrm{cm}^{2} \mathrm{sn}^{-1}\right) ; \lambda$ -ısı iletkenliği katsayısı

$\left(\mathrm{Jm}^{-1} \mathrm{sn^{-1 } \circ} \mathrm{C}^{-1}\right.$ veya watt $\left.m^{-1}{ }^{\circ} \mathrm{C}^{-1}\right) ; C_{H}$ - hacimsel ISI kapasitesi $\left(\mathrm{J} \mathrm{m}^{-3}{ }^{\circ} \mathrm{C}^{-1}\right.$ veya $\left.\mathrm{cal} \mathrm{cm}^{-3}{ }^{\circ} \mathrm{C}^{-1}\right)$; $x$ mesafe $(\mathrm{cm})^{\prime}$ dir.

Toprak katmanlarında sıcaklık değişimi sonucunda oluşan ve birim alandan gecen ISI miktarına $\left(Q, \mathrm{~J} \mathrm{~m}^{-2}\right)$ bağlı olarak, ISı iletkenliği denkleminin (Eşitlik 2) çözümünü boyutsuz biçimde inceleyelim.

Yeryüzüne ulaşan güneş radyasyonu (ISI kaynağı) sonucunda toprak yüzeyi ve alt 
katmanlar arasındaki sıcaklık farkları, dolayısıyla toprakta ISI miktarı (enerjisi) oluşmaktadır. Toprağın ısı miktarı yüzey sıcaklığına önemli düzeyde bağlı olmaktadır. Bu durumda, ısı iletkenliği denklemi (Eşitlik 2), teorik olarak $x \rightarrow \infty$ ise $T \rightarrow T_{0} \quad$ ( $T_{0}$-toprak yüzeyinin veya herhangi bir katmanın ortalama sıcaklığı) sınır koşulunu sağlamaktadır. Toprakta sıcaklığın dağılımına uygun olarak, birim alandan gecen ıSı miktarı $\left(\mathrm{J} \mathrm{m}^{-2}\right)$, aşağıdaki gibi ifade olunabilir:

$$
\begin{aligned}
& Q=\rho C_{g} \int_{-\infty}^{\infty}\left(T-T_{0}\right) d x= \\
& =2 \rho C_{g} \int_{0}^{\infty}\left(T-T_{0}\right) d x
\end{aligned}
$$

Burada, $\rho$ - toprağın özgül ağırlığı $\left(\mathrm{kgm}^{-3}\right) ; C_{g}$ gravimetrik Isı kapasitesi

$\left(\text { cal } \mathrm{gr}^{-1}{ }^{\circ} \mathrm{C}^{-1} \text { veya } \mathrm{J} \mathrm{kg}^{-1}{ }^{\circ} \mathrm{C}^{-1}\right)^{\prime}$ dir.

Aynı zamanda, bir boyutlu ısı iletkenlik denkleminin benzerlik teorisine göre çözümünde (Luikov ve Mikhailov, 1965; Luikov, 1967; Kreith ve Black, 1983; Ekberli ve ark., 2015) boyutsuz sıcaklık fonksiyonu

$\eta=\frac{x}{2 \sqrt{a t}}$

benzerlik değişkenine bağlı olmaktadır. Sıcaklık ve birim alandan geçen ısı miktarı karşılıklı etkileşimde olduklarından, boyutsuz sıcaklık fonksiyonu aşağıdaki biçimde yazılabilir (Turcotte ve Schubert, 1985):

$$
\begin{gathered}
\theta=\frac{T-T_{0}}{Q / 2 \rho C_{g} \sqrt{a t}}= \\
=\frac{2 \rho C_{g} \sqrt{a t}\left(T-T_{0}\right)}{Q}
\end{gathered}
$$

Eşitlik (5)'den görüldüğü gibi, $\theta$ değeri yalnızca $\eta$ benzerlik değişkeninin fonksiyonudur. Eşitlik (4) ve (5)'den sırasıyla elde edilen $d x=2 \sqrt{a t} d \eta$ ve $T-T_{0}=\frac{Q \theta}{2 \rho C_{g} \sqrt{a t}}$ ifadeleri Eşitlik (3)'de yerine konursa, boyutsuz sıcaklık fonksiyonu $(\theta)$ için,

$$
Q=2 \rho C_{g} \int_{0}^{\infty} \frac{Q \theta}{2 \rho C_{g} \sqrt{a t}} 2 \sqrt{a t} d \eta \text { veya }
$$

$\int_{0}^{\infty} \theta d \eta=\frac{1}{2}$

elde edilir. Isı iletkenliği denklemini boyutsuz biçimde yazmak için;

$$
T=T_{0}+\frac{Q}{2 \rho C_{g} \sqrt{a t}} \theta
$$

$$
\begin{aligned}
& \frac{\partial T}{\partial t}=\frac{Q}{2 \rho C_{g} \sqrt{a t}} \frac{d \theta}{d \eta} \frac{d \eta}{d t}+\theta \frac{Q}{2 \rho C_{g}} \frac{d}{d t}\left(\frac{1}{\sqrt{a t}}\right)=\frac{Q}{2 \rho C_{g} \sqrt{a t}} \frac{d \theta}{d \eta} \frac{x}{2 \sqrt{a}}\left(-\frac{1}{2} t^{-\frac{3}{2}}\right)+ \\
& +\theta \frac{Q}{2 \rho C_{g}} \frac{1}{\sqrt{a}}\left(-\frac{1}{2} t^{-\frac{3}{2}}\right)=-\frac{Q t^{-\frac{3}{2}}}{4 \rho C_{g} \sqrt{a}}\left(\eta \frac{d \theta}{d \eta}+\theta\right) \\
& \frac{\partial T}{\partial x}=\frac{Q}{2 \rho C_{g} \sqrt{a t}} \frac{d \theta}{d \eta} \frac{d \eta}{d x}=\frac{Q}{2 \rho C_{g} \sqrt{a t}} \frac{d \theta}{d \eta} \frac{1}{2 \sqrt{a t}} \Rightarrow \frac{\partial^{2} T}{\partial x^{2}}=\frac{Q}{2 \rho C_{g} \sqrt{a t}} \frac{d^{2} \theta}{d \eta^{2}} \frac{d \eta}{d x} \frac{1}{2 \sqrt{a t}}= \\
& =\frac{Q}{2 \rho C_{g} \sqrt{a t}} \frac{d^{2} \theta}{d \eta^{2}} \frac{1}{2 \sqrt{a t}} \frac{1}{2 \sqrt{a t}}=\frac{Q}{2 \rho C_{g} \sqrt{a t}} \frac{d^{2} \theta}{d \eta^{2}} \frac{1}{4 a t}
\end{aligned}
$$


bulunur. (8) ve (9) ifadeleri Eşitlik (2)'de yerine yazılırsa,

$$
\begin{aligned}
& -\frac{Q t^{-\frac{3}{2}}}{4 \rho C_{g} \sqrt{a}}\left(\eta \frac{d \theta}{d \eta}+\theta\right)= \\
& =a \frac{Q}{2 \rho C_{g} \sqrt{a t}} \frac{d^{2} \theta}{d \eta^{2}} \frac{1}{4 a t}
\end{aligned}
$$

veya

$$
\begin{aligned}
& -2\left(\eta \frac{d \theta}{d \eta}+\theta\right)=\frac{d^{2} \theta}{d \eta^{2}} \\
& \text { veya }-2 \frac{d}{d \eta}(\eta \theta)=\frac{d^{2} \theta}{d \eta^{2}}
\end{aligned}
$$

elde edilir. Eşitlik (10)'dan $\eta^{\prime}$ ya göre integrali alınırsa,

$$
-2 \eta \theta=\frac{d \theta}{d \eta}+C_{1}\left(C_{1} \text {-integral sabitidir }\right)
$$

bulunur. Toprakta sıcaklığın dağılımı, teorik olarak yüzeye göre simetrik olduğundan $C_{1}=0 \mathrm{kabul}$ edilir. Bu durumda, Eşitlik (11)'den

$$
\frac{d \theta}{\theta}=-2 \eta d \eta \text { olarak, } \theta=C_{2} e^{-\eta^{2}}
$$

bulunur. Integral sabitini ( $C_{2}$ ) belirlemek için, integral koşulu (Eşitlik 6) kullanılır. Eşitlik (12) ifadesi Eşitlik (6)’da göz önüne alınırsa,

$$
C_{2} \int_{0}^{\infty} e^{-\eta^{2}} d \eta=\frac{1}{2}
$$

olur. $e r f \eta=\frac{2}{\sqrt{\pi}} \int_{0}^{\eta} e^{-\eta^{2}} d \eta$ içiminde ifade olunan Gauss integral hata veya Kramp fonksiyonunun özelliğine göre (Luikov,1967),

$$
\operatorname{erf} \infty=1=\frac{2}{\sqrt{\pi}} \int_{0}^{\infty} e^{-\eta^{2}} d \eta \Rightarrow \int_{0}^{\infty} e^{-\eta^{2}} d \eta=\frac{\sqrt{\pi}}{2}
$$

olduğundan, Eşitlik (13)'den $C_{2}=\frac{1}{\sqrt{\pi}}$ bulunur. Bu durumda, Eşitlik (12) ifadesi $\theta=\frac{1}{\sqrt{\pi}} e^{-\frac{x^{2}}{4 a t}}$ biçiminde olur ve Eşitlik

ifadesinde göz önüne alınarak, toprağın ISI iletkenliği denkleminin birim alandan geçen ISI miktarının $(Q)$ değişimine bağı çözümü aşağıdaki biçimde elde edilir:

$T=T_{0}+\frac{Q}{2 \rho C_{g} \sqrt{\pi a t}} e^{-\frac{x^{2}}{4 a t}}$

Toprak katmanındaki ısı miktarının değişimine bağı ılarak, Eşitlik (14) toprak katmanındaki sıcaklığın değişiminin (soğumasının) değerlendirilmesine ve tahmin edilmesine imkân sağlamaktadır.

Toprak sıcaklığının günlük değişimi ve ısısal yayınım katsayısının değerlendirilmesi

Ondokuz Mayıs Üniversitesi Kampus Yerleşim sahasında yer alan Ziraat Fakültesinin deneme alanı $\left(41^{\circ} 21.86^{\prime}\right.$ Kuzey, $36^{\circ} 11.41^{\prime}$ Doğu koordinatlarında, deniz seviyesinden 190 m yükseklikte) toprağında yapılan sıcaklık ölçümleri Çizelge 1'de verilmiştir.

Ölçülen sıcaklık değerlerinden kullanılarak, toprağın temel ISI iletkenliği denkleminin çözümünden elde edilen

$a=\frac{\omega\left(x_{i}-x_{i+1}\right)^{2}}{2\left(\ln \left(A_{i} / A_{i+1}\right)\right)^{2}}(i=\overline{1,3})$

ifadesine (Trombotto ve Borzotta 2009; Correia ve ark. 2012; Arias-Penas ve ark. 2015; Ekberli ve Dengiz 2016; Dengiz ve Ekberli 2017) göre toprak katmanlarının hesaplanan ortalama ısısal yayınım katsayılarının ve ısısal yayınıma etki yapan parametrelerin değerleri

$$
\text { ( } T_{\text {maksimum }}, T_{\text {ortalama }}, A=T_{\text {maksimum }}-T_{\text {ortalama }} \text { ) Çizelge }
$$
2 'de verilmiştir. Eşitlik (15)'te gösterilen $A_{i}$ ve $A_{i+1}$ sırasıyla toprağın $x_{i}$ ve $x_{i+1}$ derinliklerine ait sıcaklık amplitütü değerleri; $\omega=\frac{2 \pi}{P}=\frac{6.28}{36000 s n} \approx 0.000174 s n^{-1} \quad$ açısal frekansdır. 
Çizelge 1. Toprağın ölçülen sıcaklık $\left({ }^{\circ} \mathrm{C}\right)$ değerleri

Table 1. Measured soil temperature $\left({ }^{\circ} \mathrm{C}\right)$ values

\begin{tabular}{|c|c|c|c|c|c|c|c|c|}
\hline $\begin{array}{l}\text { Tarih } \\
\text { Date }\end{array}$ & \multirow[t]{2}{*}{$\begin{array}{l}\text { Derinlik, cm } \\
\text { Depth, } \mathrm{cm}\end{array}$} & \multicolumn{6}{|c|}{$\begin{array}{l}\text { Zaman, saat } \\
\text { Time, hour }\end{array}$} & \multirow{2}{*}{$\begin{array}{l}\text { Ortalama } \\
\text { sıcaklık, }{ }^{\circ} \mathrm{C} \text { Average } \\
\text { temperature, }{ }^{\circ} \mathrm{C}\end{array}$} \\
\hline \multirow{5}{*}{19.04 .2005} & & $09^{00}$ & $11^{00}$ & $13^{00}$ & $15^{00}$ & $17^{00}$ & $19^{00}$ & \\
\hline & 0 & 19.1 & 23.0 & 33.0 & 28.6 & 21.0 & 16.0 & 23.5 \\
\hline & 10 & 15.8 & 17.3 & 22.8 & 15.7 & 15.4 & 15.5 & 17.1 \\
\hline & 20 & 14.7 & 16.5 & 21.2 & 16.3 & 15.5 & 16.2 & 16.7 \\
\hline & 50 & 14.6 & 15.5 & 15.8 & 16.0 & 15.0 & 15.0 & 15.3 \\
\hline \multirow{4}{*}{05.05 .2005} & 0 & 23.0 & 35.4 & 37.8 & 36.8 & 26.0 & 21.2 & 30.0 \\
\hline & 10 & 17.4 & 16.6 & 22.1 & 17.5 & 17.4 & 16.6 & 17.9 \\
\hline & 20 & 14.5 & 15.5 & 19.0 & 14.5 & 15.3 & 15.4 & 15.7 \\
\hline & 50 & 13.0 & 13.8 & 14.2 & 14.2 & 14.0 & 13.8 & 13.8 \\
\hline \multirow{4}{*}{14.06 .2005} & 0 & 31.5 & 38.4 & 43.8 & 42.0 & 37.8 & 25.4 & 36.5 \\
\hline & 10 & 22.4 & 22.9 & 27.8 & 23.2 & 22.4 & 23.2 & 23.7 \\
\hline & 20 & 21.6 & 21.8 & 26.0 & 22.6 & 22.1 & 22.4 & 22.8 \\
\hline & 50 & 15.7 & 16.9 & 16.1 & 15.6 & 16.2 & 16.3 & 16.1 \\
\hline
\end{tabular}

Çizelge 2. Isısal yayınıma etki yapan parametrelerin ve ısısal yayınım katsayılarının değerleri

Table 2. The values of the parameters affecting the thermal diffusion and coefficients of thermal diffusion

\begin{tabular}{|c|c|c|c|c|c|}
\hline $\begin{array}{l}\text { Tarih } \\
\text { Date }\end{array}$ & $\begin{array}{c}\text { Derinlik, cm } \\
\text { Depth, } \mathrm{cm}\end{array}$ & $T_{\text {maksimum }},{ }^{\circ} \mathrm{C}$ & $T_{\text {ortalama }},{ }^{\circ} \mathrm{C}$ & $A,{ }^{\circ} \mathrm{C}$ & $a, \mathrm{~m}^{2} \mathrm{sn}^{-1}$ \\
\hline \multirow{4}{*}{ 19.04.2005 } & 0 & 33.0 & 23.5 & 9.5 & \\
\hline & 10 & 22.8 & 17.1 & 5.7 & $0.33 \cdot 10^{-5}$ \\
\hline & 20 & 21.2 & 16.7 & 4.5 & $1.56 \cdot 10^{-5}$ \\
\hline & 50 & 16.0 & 15.3 & 0.7 & $0.23 \cdot 10^{-5}$ \\
\hline \multirow{4}{*}{05.05 .2005} & 0 & 37.8 & 30.0 & 7.8 & \\
\hline & 10 & 22.1 & 17.9 & 4.2 & $0.23 \cdot 10^{-5}$ \\
\hline & 20 & 19.0 & 15.7 & 3.3 & $1.50 \cdot 10^{-5}$ \\
\hline & 50 & 14.2 & 13.8 & 0.4 & $0.18 \cdot 10^{-5}$ \\
\hline \multirow{4}{*}{14.06 .2005} & 0 & 43.8 & 36.5 & 7.3 & \\
\hline & 10 & 27.8 & 23.7 & 4.1 & $0.26 \cdot 10^{-5}$ \\
\hline & 20 & 26.0 & 22.8 & 3.2 & $1.42 \cdot 10^{-5}$ \\
\hline & 50 & 16.9 & 16.1 & 0.8 & $0.41 \cdot 10^{-5}$ \\
\hline
\end{tabular}

Tmaksimum, Tortalama, A, a: toprak katmanındaki sırasıyla maksimum ve ortalama sıcaklık $\left({ }^{\circ} \mathrm{C}\right)$, amplitüt $\left({ }^{\circ} \mathrm{C}\right)$, ısısal yayınım katsayısı $\left(\mathrm{m}^{2} \mathrm{sn}^{-1}\right)$

Tmaksimum, Tortalama, A, a: maximum and average temperature $\left({ }^{\circ} \mathrm{C}\right)$, amplitude $\left({ }^{\circ} \mathrm{C}\right)$, thermal diffusion coefficient $\left(\mathrm{m}^{2} \mathrm{sec} \mathrm{c}^{-1}\right)$ in the soil layer, respectively

Çizelge 1 ve 2'den görüldüğü gibi, toprak yüzeyinden derinlere doğru inildikçe minimum sıcaklıkta değişim (katmanlar arasındaki sıcaklık farkı) az olmaktadır. Maksimum sıcaklıkta da düşüş eğilimi görülmekte, minimum sıcaklıkla karşılaştırıldığında katmanlar arasındaki sıcaklık değişimi daha fazla olmaktadır. Genel olarak, alt katmanlara doğru ortalama günlük sıcaklığın değişimi düşük düzeyde gerçekleşmektedir. Toprak katmanlarındaki sıcaklık dalgalarının amplitütü, teorik olarak toprak derinliği boyunca ekspansiyonel olarak azalmaktadır. Toprak özellikleriyle beraber, toprak katmanlarının ortalama ve maksimum sıcaklığı amplitütü önemli düzeyde etkilemektedir. Alt katmanlarda ortalama sıcaklığın ve sıcaklık değişiminin (dolayısıyla maksimum sıcaklığın) düşük olması, amplitütün azalmasına neden olan önemli faktörlerdir. Yüzey sıcaklığının toprağın $10-20 \mathrm{~cm}$ katmanına daha fazla etkisi sonucunda bu katmada sıcaklık değişimi kararlılık göstermekte ve ısısal yayınım katsayısı daha fazla olmaktadır. Alt toprak katmanlarında sıcaklı değişiminin, dolayısıyla Isı iletiminin az olması ısısal yayınımın düşük olmasına neden olan önemli faktörlerdendir.

Genel olarak, iklimsel faktörlerle beraber Isısal yayınıma önemli düzeyde etki yapan toprak özelliklerindeki düzensiz değişim, toprak özelliklerinin bir birine olan karşılıklı etkisi, horizon derinliği, sıcaklık dalgalarının frekansı vb. ısısal yayınımın orantısız değişimine ve farklı 
değerlere sahip olmasına sebep olmaktadır (Arkhangel'skaya ve ark., 2005; Tikhonravova, 2007; Arkhangel'skaya ve Umarova, 2008; Dengiz ve Ekberli, 2017).

Sıcaklık değişimine bağlı olarak toprağın ısı miktarının ( $Q$ ) belirlenmesi

Toprağın ISI miktarı hacimsel ISI kapasitesi, hacim ve sıcaklık değişimiyle doğrusal orantılı olup, aşağıdaki gibi ifade olunmaktadır:

$$
\begin{aligned}
& Q=C_{H} V\left(T i-T_{i+1}\right)= \\
& =C_{H} V \Delta T(i=\overline{1,3})
\end{aligned}
$$

Burada, $C_{H}$ - toprağın hacimsel ISI kapasitesi ( cal cm ${ }^{-3}{ }^{\circ} \mathrm{C}^{-1}$ veya $\left.\mathrm{J} \mathrm{m}^{-3}{ }^{\circ} \mathrm{C}^{-1}\right) ; V$-birim hacim $\mathrm{cm}^{3}$ veya $\left.\mathrm{m}^{3}\right) ; \Delta T$ - toprağın $x_{i}$ ve $x_{i+1}$ derinliklerindeki ortalama sıcaklık farkı $\left({ }^{\circ} \mathrm{C}\right)$ 'dır.

\section{Toprağın gravimetrik ısı kapasitesi}

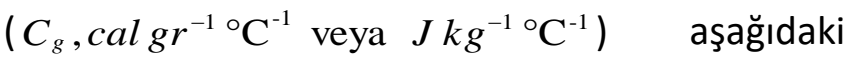
ifade ile hesaplanmaktadır (Hanks ve Ashcroft 1980; Hilel 2004):

$$
C_{g}=C_{\text {org }} \frac{m_{\text {org }}}{m}+C_{\min }\left(1-\frac{m_{\text {org }}}{m}\right)
$$

Burada, $C_{\text {org }}$ ve $C_{\min }$ - sırasıyla topraktaki organik maddenin ve mineral maddenin özgül ISI kapasitesi $\left(\right.$ cal $g r^{-1}{ }^{\circ} \mathrm{C}^{-1}$ veya $\left.J k^{-1}{ }^{\circ} \mathrm{C}^{-1}\right) ; \frac{m_{\text {org }}}{m}$ - topraktaki organik madde miktarı $\left(g g r^{-1}\right.$ veya \%) olmaktadır. Araştırma toprağında $\quad C_{\text {org }}=0.46 \mathrm{cal} \mathrm{gr}^{-1}{ }^{\circ} \mathrm{C}^{-1}$; $\frac{m_{\text {org }}}{m}=0.0283 \mathrm{grgr}^{-1} ; \quad C_{\min }=0.22 \mathrm{cal} \mathrm{gr}^{-1}{ }^{\circ} \mathrm{C}^{-1}$ olduğunu göz önüne alarak, $C_{g}=0.227$ cal gr $^{-1}{ }^{\circ} \mathrm{C}^{-1}=950.404$ $J k^{-1}{ }^{\circ} \mathrm{C}^{-1}$ elde edilir.
Toprağın hacimsel ısı kapasitesi $\left(C_{H}\right)$

$$
C_{H}=C_{g} \rho_{v}+C_{s} W_{\theta}
$$

şeklinde ifade edilir. Burada, $\rho_{v}$-toprağın hacim ağırlığı (1.12 $\left.\mathrm{grcm}^{-3}\right) ; \quad C_{s}$-suyun hacimsel ISI kapasitesi $\left(1.00 \mathrm{cal} \mathrm{cm}^{-3}{ }^{\circ} \mathrm{C}^{-1}\right) ; W_{\theta}$ - toprağın hacimsel nem $\left(\mathrm{cm}^{3} \mathrm{~cm}^{-3}\right)$ içeriğini göstermektedir. Bu değerlere göre toprağın hacimsel ısı kapasitesi $\left(C_{H}\right)$ aşağıdaki ifadeye göre belirlenmektedir:

$$
\begin{aligned}
& C_{H}=0.227 \mathrm{cal} \mathrm{gr}^{-1}{ }^{\circ} \mathrm{C}^{-1} \cdot 1.12 \mathrm{grcm}^{-3}+ \\
& +1.00 \mathrm{cal} \mathrm{cm}^{-3}{ }^{\circ} \mathrm{C}^{-1} W_{\theta} \\
& C_{H}=\left(0.254+W_{\theta}\right) \mathrm{cal} \mathrm{cm}^{-3}{ }^{\circ} \mathrm{C}^{-1}
\end{aligned}
$$

Genel olarak, toprağın ISı kapasitesi toprağın mineralojik yapısına ve bünyesine, organik madde miktarına, nem içeriğine, gözenekliliğine ve havasına bağlı olup, Eşitlik (19)'dan da görüldüğü gibi, toprak neminin artması durumunda, hacimsel ISI kapasitesi doğrusal olarak artmaktadır.

Toprağın gravimetrik ISI kapasitesi, hacimsel nem içeriği ve toprağın $x_{i}$ ve $x_{i+1}$ derinliklerindeki ortalama sıcaklık değerleri arasındaki farka $(\Delta T)$ bağlı olarak Eşitlik (19) ve (16) ifadelerinden sırasıyla hesaplanan hacimsel ISI kapasitesi ve ISI miktarı değerleri Çizelge 3'de verilmiştir.

Çizelge 3'den görüldüğü gibi, katmanlar üzere hacimsel Isı kapasitesi dar aralıkta değişmektedir. Toprağın ısı miktarı ise geniş aralıkta değişmekte, katman derinliklerindeki ortalama sıcaklık farkı Isı miktarının artışına neden olan temel faktör olmaktadır. Dolayısıyla, toprakta ISı miktarının korunması, katmanlardaki sıcaklık değişiminin korunması ile ilişkili olmaktadır. Günlük hava koşullarının çabuk değişimi, termo fiziksel parametreler arasında düzenli (orantılı) olmayan farklara neden olmaktadır. Genel olarak, net radyasyon, gizli Isı akışı, evapotranspirasyon gibi faktörlerde ISI miktarını önemli düzeyde etkilemektedir. 
Çizelge 3. Toprağın bazı termo-fiziksel parametre değerleri Table 3. Some thermo-physical parameter values of soil

\begin{tabular}{|c|c|c|c|c|c|c|}
\hline $\begin{array}{l}\text { Tarih } \\
\text { Date }\end{array}$ & $\begin{array}{l}\text { Derinlik, } \mathrm{cm} \\
\text { Depth, } \mathrm{cm}\end{array}$ & $\begin{array}{c}C_{g}, \\
J k g^{-1}{ }^{\circ} \mathrm{C}^{-1}\end{array}$ & $\frac{W, \%}{W_{\theta}, \mathrm{cm}^{3} \mathrm{~cm}^{-3}}$ & $\Delta T,{ }^{\circ} \mathrm{C}$ & $\begin{array}{l}C_{H} \cdot 10^{6}, \\
J m^{-3}{ }^{\circ} \mathrm{C}^{-1}\end{array}$ & $Q, J m^{-2}$ \\
\hline \multirow{3}{*}{ 19.04.2005 } & $0-10$ & \multirow{3}{*}{950.404} & $\frac{28.78}{0.321}$ & 6.4 & 2.407 & $1.541 \cdot 10^{7}$ \\
\hline & $10-20$ & & $\underline{32.02}$ & 0.4 & 2.567 & $1.027 \cdot 10^{6}$ \\
\hline & $20-50$ & & $\frac{33.88}{0.380}$ & 1.4 & 2.654 & $3.716 \cdot 10^{6}$ \\
\hline \multirow{3}{*}{05.05 .2005} & $0-10$ & \multirow{3}{*}{950.404} & $\frac{30.25}{0.339}$ & 12.1 & 2.483 & $3.004 \cdot 10^{7}$ \\
\hline & $10-20$ & & $\frac{32.36}{0.362}$ & 2.2 & 2.579 & $5.674 \cdot 10^{6}$ \\
\hline & $20-50$ & & $\frac{32.05}{0.359}$ & 1.9 & 2.567 & $4.877 \cdot 10^{6}$ \\
\hline \multirow{3}{*}{14.06 .2005} & $0-10$ & \multirow{3}{*}{950.404} & $\frac{31.01}{0.348}$ & 12.8 & 2.521 & $3.227 \cdot 10^{7}$ \\
\hline & $10-20$ & & $\frac{31.98}{0.358}$ & 0.9 & 2.562 & $2.306 \cdot 10^{6}$ \\
\hline & $20-50$ & & $\frac{26.89}{0.301}$ & 6.7 & 2.324 & $1.557 \cdot 10^{7}$ \\
\hline
\end{tabular}

$\mathrm{C}_{\mathrm{g}}$ : toprağın gravimetrik ısı kapasitesi (cal $\mathrm{gr}^{-1}{ }^{\circ} \mathrm{C}^{-1}$ veya $\mathrm{J} \mathrm{kg}^{-1}{ }^{\circ} \mathrm{C}^{-1}$ ), $W_{\theta}$ : toprağın hacimsel nem içeriği $\left(\mathrm{cm}^{3} \mathrm{~cm}^{-3}\right), \Delta T$ : toprağın $x_{i}$ ve $x_{i+1}$ derinliklerindeki ortalama sıcaklık farkı $\left({ }^{\circ} \mathrm{C}\right)$, $\mathrm{CH}_{\mathrm{H}}$ : hacimsel Isı kapasitesi $\left(\mathrm{J} \mathrm{m}^{-3}{ }^{\circ} \mathrm{C}^{-1}\right), Q$ : toprağın ısı miktarı $\left(\mathrm{J} \mathrm{m}^{-2}\right)$

$\mathrm{C}_{\mathrm{g}}$ : soil gravimetric heat capacity $\left(\mathrm{cal} \mathrm{gr}{ }^{-1}{ }^{\circ} \mathrm{C}^{-1}\right.$ veya $\left.\mathrm{J} \mathrm{kg}^{-1}{ }^{\circ} \mathrm{C}^{-1}\right), W_{\theta}$ : volumetric moisture content of the soil $\left(\mathrm{cm}^{3} \mathrm{~cm}^{-3}\right), \Delta T$ : average temperature difference at $x_{i}$ and $x_{i+1}$ depths of soil $\left({ }^{\circ} \mathrm{C}\right), \mathrm{C}_{\mathrm{H}}$ : volumetric heat capacity $\left(\mathrm{J} \mathrm{m}^{-3}{ }^{\circ} \mathrm{C}^{-1}\right), Q$ : amount of heat in the soil $\left(\mathrm{J} \mathrm{m}^{-2}\right)$

Toprak katmanında ısı miktarına bağlı olarak sıcaklığın zaman göre değişimi

Farklı toprak katmanlarındaki ısı miktarı ve ISı miktarının değişimi toprak sıcaklığına etki yapan temel faktörlerden biridir. Sürekli olarak güneş radyasyonunun etkisi altında olan toprak yüzeyinde oluşan farklı ISı miktarı, toprak katmanlarındaki sıcaklık değişimlerine neden olmaktadır. Toprak yüzeyinde ısı miktarının sabit olması durumunda, katmanlardaki sıcaklık değişimi fazla olmamaktadır.

Farklı toprak katmanlarındaki sıcaklığın zamana ve derinliğe göre değişimi, Eşitlik (14) ifadesi kullanılarak farklı ısı miktarı değerlerinde teorik olarak hesaplanabilir. Farklı dönemlerde ve ISI miktarında toprağın $0-10 \mathrm{~cm}$ katmanındaki sıcaklığın zamana göre değişimi Şekil 1'de gösterilmiştir. Görüldüğü gibi, ısı miktarının 1.541. $10^{7} \mathrm{~J} \mathrm{~m}^{-2} ; 3.004 \cdot 10^{7} \mathrm{~J} \mathrm{~m}^{-2}$ ve $3.227 \cdot 10^{7} \mathrm{~J} \mathrm{~m}^{-2}$ sabit değerlerinde, 10 saat boyunca kaybedilen ISI işleminden sonra, toprağın 0-10 cm katmanında sıcaklığın sırasıyla \%34.72; \%57.13 ve \%55.68 azaldığı tahmin edilmiştir. Sıcaklık ölçümü zamanındaki hava koşulları, toprağın termofiziksel özelliklerinin değişimi, ısı miktarının sabit kabul edilmesi vb. gibi faktörler, sıcaklığının düzensiz azalmasına neden olan faktörler olabilir. 


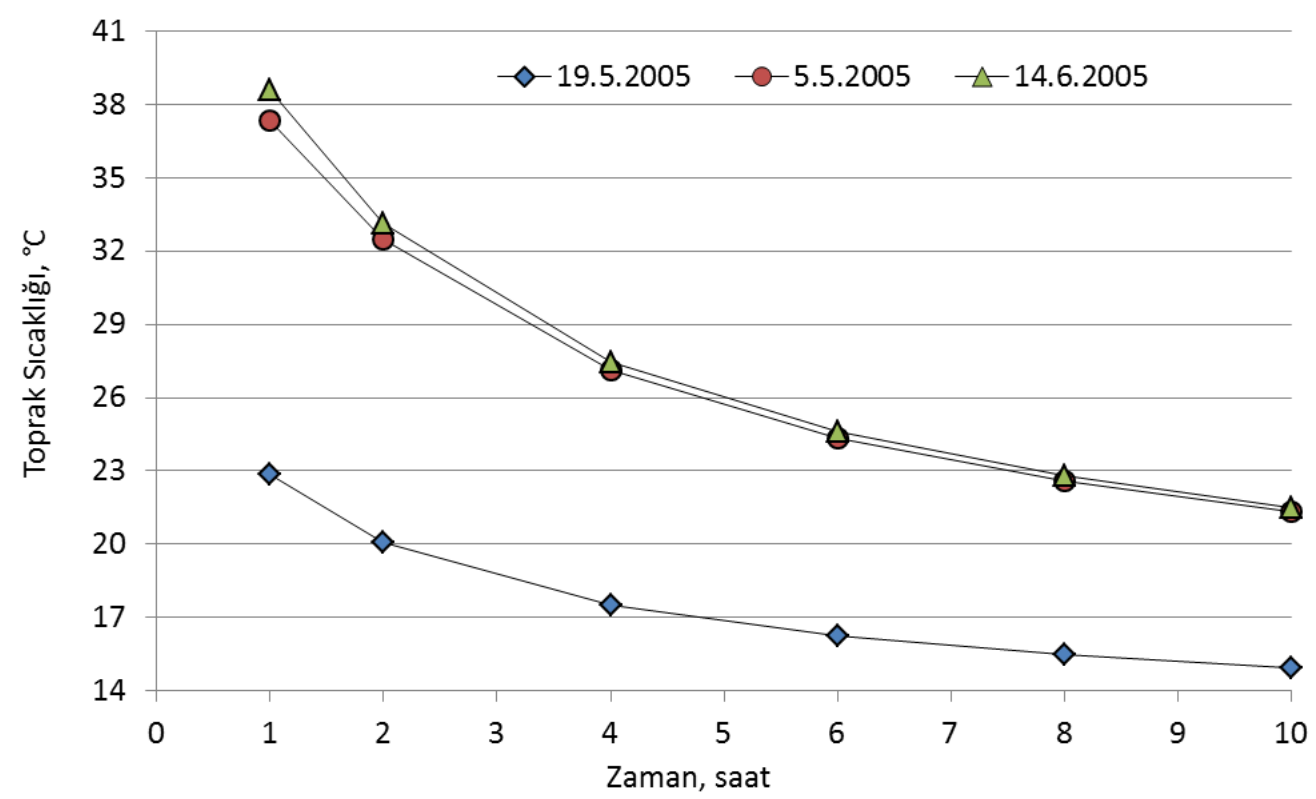

Şekil 1. Isı miktarına bağlı olarak toprağın 0-10 cm katmanında sıcaklığın zamana göre değişimi

Figure 1.Temperature change over timed depending on the amount of heat in $0-10 \mathrm{~cm}$ layer of soil

Toprağın $10-20 \mathrm{~cm}$ ve $20-50 \mathrm{~cm}$ katmanlarında ise sıcaklığın çok düşük düzeyde değişimi (azalması) tahmin edilmiştir. Bu durum ISI kaybının derin toprak katmanlarında daha yüksek, katmanlar arasındaki sıcaklık farkının düşük olmasının yanı sıra aynı zamanda the modelin tüm termo-fiziksel parametreleri kapsamamasından da kaynaklanabilir.

Ayrıca, Eşitlik (14) ifadesinden görüldüğü gibi toprak yüzeyinden $x$ mesafesinde, sıcaklık zamana göre artarak maksimum değerini almakta, sonra ise azalmaktadır. Fonksiyonun maksimum değerinin belirlenmesi koşuluna göre, Eşitlik (14)'den

$$
\frac{d T}{d t}=\frac{d T}{d t}=\frac{Q}{2 \rho C_{g} \sqrt{\pi a}} e^{-\frac{x^{2}}{4 a t}}\left(-\frac{1}{2 t \sqrt{t}}+\frac{x^{2}}{4 a t^{2} \sqrt{t}}\right)=0
$$

yazılarak, sıcaklığın maksimum değerine uygun olan zaman $t=\frac{x^{2}}{2 a}$ olarak elde edilir.

\section{Sonuç}

Toprağın bir boyutlu temel ISI iletkenliği denklemi benzerlik yöntemine göre irdelenmiş; toprak katmanının soğuma sürecinde sıcaklığın değişimi ile ısı miktarı, toprağın özgül ağırlı̆̆ı ve gravimetrik Isı kapasitesi, Isısal yayınım katsayısı, toprak derinliği arasında fonksiyonel ilişkiyi gösterenanalitik bir ifade saptanmıştır. IsI miktarının sabit olması durumunda, yüzey toprak katmanında sıcaklık değişiminin daha yüksek olduğu tahmin edilmiştir. Isı miktarı ve toprak tabakasının derinliği tarafından kontrol edilen ISI kaybı sürecinde toprak sıcaklığının azaldığı teorik olarak tespit edilmiştir. Yüzey toprak sıcaklığının toprak profilindeki ısı değişimi üzerinde önemli bir etkiye sahip olduğu ve yüzey toprak katmanlarının bu ISI değişiminden daha fazla etkilendiği belirlenmiştir. Toprağın soğuması sürecinde, yüzey toprak katmanlarından kaynaklanan ISI kaybı, derin toprak katmanlarından daha yüksektir. Genel olarak, matematiksel modellerin oluşturulmasında ve uygulanmasında varsayımlar yapılmasından kaynaklanan noksanların aradan kaldırıması için varsayımların azaltılması gerekmektedir. Bu nedenle, daha fazla termofiziksel özellikleri göz önüne alarak, kullanılan analitik ifadenin daha da genelleştirilmesi mümkün olabilir.

Çıkar Çatışması Beyanı: Makale yazarları aralarında herhangi bir çıkar çatışması olmadığını beyan ederler.

\section{Kaynaklar}

Afify, A.A. (2009). Similarity solution in MHD: Effects of thermal diffusion and diffusion thermo on free convective heat and mass transfer over a stretching surface considering suction or injection. Commun Nonlinear Sci Numer Simulat, 14, 2202-2214. 
Antonopoulos, V.Z. (2006). Water movement and heat transfer simulations in a soil under ryegrass. Biosystems Engineering, 95 (1), 127-138.

Arias-Penas, D., Castro-Garcia, M.P, Rey-Ronco, M.A, \& Alonso-Sanchez, T. (2015). Determining the thermal diffusivity of the ground based on subsoiltemperatures. Preliminary results of an experimental geothermalborehole study QTHERMIEUNIOVI. Geothermics, 54, 35-42.

Arkhangel'skaya, T.A., Guber, A.K., Mazirov, M.A., \& Prokhorov, M.V. (2005). The temperature rejime of soils in Vladimir Opol'e Region. Pocvovedeniye, 7, 832-843.

Arkhangel'skaya, T.A., \& Umarova, A.B. (2008). Thermal diffusivity and temperature regime of soils in large lysimeters of the experimental soil station of Moscow State University. Pocvovedeniye, 3, 311320.

Barraza, V., Grings, F., Franco,M., Douna, V., Entekhabi, D., Restrepo-Coupe, N., Huete, A., Gassmann, M., \& Roitberg, E. (2019). Estimation of latent heat flux using satellite land surface temperature and a variational data assimilation scheme over a eucalypt forest savanna in Northern Australia. Agricultural and Forest Meteorology, 268, 341-353.

Braud, I., Dantas-Antonino, A.C., Vauclin, M., Thony, J.L., \& Ruelle, P. (1995). A simple soil-plant-atmosphere transfer model (SiSPAT) development and field verification. Journal of Hydrology, 166 (3-4), 213-250.

Camillo, P.J., Gurney, R.J., \& Schmugge, T.J. (1983). A soil and atmospheric boundary layer model for evapotranspiration and soil moisture studies. Water Resources Research, 19 (2), 371-380.

Chen, S., Mao, J., \& Han, X. (2016). Heat transfer analysis of a vertical ground heat exchanger usingnumerical simulation and multiple regression model. Energy and Buildings, 129, 81-91.

Cichota, R., Elias, E.A., \& van Lier, Q.J. (2004). Testing a finite-difference model for soil heat transfer by comparing numerical and analytical solutions. Environmental Modelling \& Software, 19, 495-506.

Correia, A., Vieira, G., \& Ramos, M. (2012). Thermal conductivity and thermal diffusivity of cores from a 26 meter deep borehole drilled in Livingston Island, Maritime Antarctic. Geomorphology, 155(156), 7-11.

Dengiz, O, \& Ekberli, i. (2017). Bazı vertisol alt grup topraklarının fizikokimyasal ve ısısal özelliklerinin incelenmesi. Akademik Ziraat Dergisi, 6(1), 45-52.

Ding, R., Kang, S., Li, F., Zhang, Y., \& Tong, L. (2013). Evapotranspiration measurement and estimation using modified Priestley-Taylor model in an irrigated maize field with mulching. Agricultural and Forest Meteorology, 168 (1), 140-148.

Ekberli, İ., \& Dengiz, O. (2016). Bazı ınceptisol ve entisol alt grup topraklarının fizikokimyasal özellikleriyle ısısal yayınım katsayısı arasındaki regresyon ilişkilerin belirlenmesi. Toprak Su Dergisi, 5(2), 1-10.

Ekberli, i.., Dengiz O, Gülser C, \& Özdemir N, (2016). Benzerlik teorisinin toprak sıcaklığına uygulanabilirliği. Toprak Bilimi ve Bitki Besleme Dergisi 4 (2), 63-68.

Ekberli, ì., \& Gülser, C. (2014). Estımatıon of soil temperature by heat conductıvity equatıon. Vestnik
Bashkir State Agrarian University (Вестник Башкирского Государственного Аграрного Университета), 2 (30), 12-15.

Ekberli, i.., \& Gülser, C. (2015). Iki boyutlu ISı iletkenliği denklemine bağlı olarak toprak sıcaklığının matematiksel modellenmesi Anadolu Tarım Bilim. Dergisi, 30 (3), 287-291.

Ekberli, İ., \& Gülser, C. (2016). Toprağın ısısal yayınımının fonksiyonel değişimi ve toprak sıcaklığına etkisi. Anadolu Tarım Bilimleri Dergisi, 31 (2), 294-300.

Ekberli, İ., Gülser, C., \& Mamedov, A. (2015). Toprakta bir boyutlu Isı iletkenlik denkleminin incelenmesinde benzerlik teorisinin uygulanması. Süleyman Demirel Üniversitesi Ziraat Fakültesi Dergisi, 10(2), 69-79.

Ekberli, İ., Gülser, C., \& Özdemir, N. (2017). Farklı toprak derinliklerindeki sıcaklığın tahmininde parabolik fonksiyonun kullanımı. Toprak Bilimi ve Bitki Besleme Dergisi, 5 (1), 34- 38.

Ekberli, i., \& Sarılar, Y. (2014). Investıgating soil temperature variabılity and thermal diffusivity in grass cowered and shaded areas by trees. Почвоведение и Агрохимия (Soil Science and Agrochemistry, Almaty), № 4, Алматы, pp. 17-30.

Ekberli, İ., \& Sarılar, Y. (2015). Toprak sıcaklığının profil boyunca sönme derinliğinin ve gecikme zamanının belirlenmesi. Ege Üniversitesi Ziraat Fakültesinin Dergisi, 52 (2), 219-225.

Eshonkulov, R., Poyda, A., Ingwersen, J., Pulatov, A., \& Streck, T. (2019). Improving the energy balance closure over a winter wheat field by accounting for minor storage terms. Agricultural and Forest Meteorology, 264, 283-296.

Evett, S.R., Agam, N., Kustas, W.K., Colaizzi, P.D., \& Schwartz, R.C. (2012). Soil profile method for soil thermal diffusivity, conductivity and heat flux: Comparison to soil heat flux plates. Advances in Water Resources, 50, 41-54.

Gülser, C., \& Ekberli, I. (2004). A comparison of estimated and measured diurnal soil temperature through a clay soil depth. Journal of Applied Sciences, 4(3), 418-423.

Gülser, C., Ekberli, İ., \& Mamedov, A. (2019). Toprak Sıcaklığının Yüzey Isı Akışına Bağlı Olarak Değişimi. Yüzüncü Yıl Üniversitesi Tarım Bilimleri Dergisi, 29(1), 1-9.

Gülser, C., Ekberli, i., Mamedov, A., \& Özdemir, N. (2018). Faz değişimine bağlı olarak ısı iletkenliği denkleminin incelenmesi ve toprak neminin ısısal yayınıma etkisi. Anadolu Tarım Bilimleri Dergisi 33 (3), 261-269.

Goldstein, R.J., Ibele, W.E., Patankar, S.V., Simon, T.W., Kuehn, T.H., Strykowski, P.J., Tamma, K.K., Heberlein, J.V.R., Davidson, J.H., Bischof, J., Kulacki, F.A., Kortshagen, U., Garrick, S., Srinivasan, V., Ghosh, K. \& Mittal, R. (2010a). Heat transfer-A review of 2004 literature. International Journal of Heat and Mass Transfer, 53, 4343-4396.

Goldstein, R.J., Ibele, W.E., Patankar, S.V., Simon, T.W., Kuehn, T.H., Strykowski, P.J., Tamma, K.K., Heberlein, J.V.R., Davidson, J.H., Bischof, J., Kulacki, F.A., Kortshagen, U., Garrick, S., Srinivasan, V., Ghosh, K., \& Mittal, R. (2010b). Heat transfer-A review of 2005 literature. International Journal of Heat and Mass Transfer, 53, 4397-4447. 
Hanks, R.J., \& Ashcroft, G.J. (1980). Applied soil physics. Soil water and temperature applications. Springer-Verlag Berlin Heidelberg, pp. 125-144.

Hilel, D. (2004). Introduction to environmental soil physics. Elsevier Academic Press, USA, pp. 215-233.

Holmes, T.R.H., Owe, M., De Jeu, R.A.M., \& Kooi, H. 2008. Estimating the soil temperature profile from a single depth observation: A simple empirical heatflow solution. Water Resources Research, 44 (2), W0241, 1-11.

Hu, G., Zhao, L., Wu X., Li, R., Wu, T., Xie, C., Qiao, Y., Shi, J., Li, W., \& Cheng, G. (2016). New Fourier-series-based analytical solution to the conduction-convection equation to calculate soil temperature, determine soil thermal properties, or estimate water flux. International Journal of Heat and Mass Transfer, 95, 815-823.

Huang, F., Zhan, W., Ju, W., \& Wang, Z. (2014). Improved reconstruction of soil thermal field using two-depth measurements of soil temperature. Journal of Hydrology, 519, 711-719.

Ihsak, A., (2010). Similarity solutions for flow and heat transfer over a permeable surface with convective boundary condition. Applied Mathematics and Computation 217, 837-842.

Jia, X., Zha, T.S., Gong, J.N., Wu, B., Zhang, Y.Q., Qin, S.G., Chen, G.P., Feng, W., Kellomaki, S., \& Peltola, H. (2016). Energy partitioning over a semi-arid shrubland in northern China. Hydrological Processes. 30 (6), 972-985.

Krarti, M., Lopez-Alonzo, C., Claridge, D.E., \& Kreider, J.F. (1995). Analytical model to predict annual soil surface temperature variation. Journal of Solar Energy Engineering, 177, 91-99.

Kreith, F., \& Black, W.Z. (1983). Bazic Heat Transfer (in Russian). Press Mir, Moscow, 512 p.

Kutikoff, S., Lin, X., Evett, S., Gowda, P., Moorhead, J., Marek, G., Colaizzi, P., Aiken, R., \& Brauer. D. (2019). Heat storage and its effect on the surface energy balance closure under advective conditions. Agricultural and Forest Meteorology, 265, 56-69.

Kuznetsov, G.V., Osipov, K.Yu., Piskunov, M.V., \& Volkov, R.S. (2018). Experimental research of radiative heat transfer in a water film. International Journal of Heat and Mass Transfer, 117, 1075-1082.

Lettau, H.H. (1954). Improved models of thermal diffusion in the soil. Transactions of the American Geophysical Union, 35(1), 121-132.

Liang, H., Hu, K., Qin, W., Zuo, Q., \& Zhang, Y. (2017). Modelling the effect of mulching on soil heat transfer, watermovement and crop growth for ground cover rice production system. Field Crops Research, 201, 97-107.

Liu, B.C., Liu, W., \& Peng, S.W. (2005). Study of heat and moisture transfer in soil with a dry surface layer. International Journal of Heat and Mass Transfer, 48, 4579-4589.

Luikov, A.V. (1967). Theory of thermal conductivity (in Russian). Vysshaya Shkola Press, Moscow, $599 \mathrm{p}$.

Luikov, A.V., \& Mikhailov, YuA (1965). Theory of energy and mass transfer. Pergamon Press, Oxford, England, 392 p.

Ma, J., Zha, T., Jia,X., Tian, Y., Bourque, C.P.-A., Liu, P., Bai,
Y., Wu, Y., Ren, C., Yu, H., Zhang, F., Zhou, C., \& Chen, W. (2018). Energy and water vapor exchange over a young plantation in northern China. Agricultural and Forest Meteorology, 263, 334-345.

Milly, P.C.D. (1986). An event-based simulation model of moisture and energy fluxes at a bare soil surface. Water Resources Research, 22 (12), 1680-1692.

Novak, M.D., \& Black, T.A. (1985). Theoretical determination of the surface energy balance and thermal regimes of bare soils. Boundary-Layer Meteorology, 33 (4), 313-333.

Okoya, S.S. (2001). Simılarity temperature profiles for some nonlinear reaction - diffusion equations. Mechanics Research Communications, 28(4), 477-484.

Oncley, S.P., Foken, T., Vogt, R., Kohsiek, W., DeBruin, H.A.R., Bernhofer, C., Christen, A., van Gorsel, E., Grantz, D., Feigenwinter, C., Lehner, I., Liebethal, C., Liu, H., Mauder, M., Pitacco, A., Ribeiro, L., \& Weidinger, T. (2007). The energy balance experiment EBEX-2000. Part I: overview and energy balance. Boundary-Layer Meteorology, 123, 1-28.

Oosterkamp, A., Ytrehus, T., \& Galtung, S.T. (2016). Effect of the choice of boundary conditions on modelling ambient to soil heat transfer near a buried pipeline. Applied Thermal Engineering, 100, 367-377.

Passerat de Silans, A., Bruckler, L., Thony, J.L., \& Vanclin, M. (1989). Numerical modeling of coupled heat and water flows during drying in a stratified bare soil Comparison with field observations. Journal of Hydrology, 105 (1-2), 109-138.

Passerat de Silans, A.M.B., Monteny, B.A., Lhomme, J.P. (1996). Apparent soil thermal diffusivity, a case study: HAPEX-Sahel experiment. Agricultural and Forest Meteorology, 81, 201-216.

Qi. J., Zhang, X., \& Cosh, M.H. (2019). Modeling soil temperature in a temperate region: A comparison between empirical and physically based methods in SWAT. Ecological Engineering, 129, 134-143.

Russell, E.S., Liu, H., Gao, Z., Finn, D., \& Lamb, B. (2015). Impacts of soil heat flux calculation methods on thesurface energy balance closure. Agricultural and Forest Meteorology, 214-215, 189-200.

Samanta, S., \& Guha, A. (2012). A similarity theory for natural convection from a horizontal plate for prescribed heat flux or wall temperature. International Journal of Heat and Mass Transfer, 55, 3857-3868.

Swain, M., Swain, M., Lohmann, M., \& Swain, E. (2012). Experimental determination of soil heat storage for the simulation of heat transport in a coastal wetland. Journal of Hydrology, 422-423, 53-62.

Thiery, D., Amraoui. N., \& Noyer, M-L. (2018). Modelling flow and heat transfer through unsaturated chalk Validation with experimental data from the ground surface to the aquifer. Journal of Hydrology, 556, 660-673.

Tikhonravova, P.I. (2007). Effect of the water content on the thermal diffusivity og clay loams with different degrees of salinization in the Transvolga region. Pocvovedeniye, 1, 55-59.

Trombotto, D., \& Borzotta, E. (2009). Indicators of present global warming through changes in active layerthickness, estimation of thermal diffusivity and 
geomorphological observations in the Morenas Coloradas rockglacier, Central Andes of Mendoza, Argentina. Cold Regions Science and Technology, 55, 321-330.

Turcotte, D.L., \& Schubert, G. (1985). Geodynamics. Applications of continuum physics to geological problems (Volume 1). Mir Press, Moscow, $376 \mathrm{p}$.

van Lopik, J. H., Hartog, N., Zaadnoordijk, W.J., Cirkel, D.G., \& Raoof, A. (2015). Salinization in a stratified aquifer induced by heat transfer from wel lcasings. Advances in Water Resources, 86, 32-45.

Xu, G., Li, Y., Deng, H., Li, H., \& Yu, X. (2015). The application of similarity theory for heat transfer investigation in rotational internal cooling channel. International Journal of Heat and Mass Transfer, 85, 98-109.

Zhang, Y., Zhao, W., He, J., \& Zhang, K. (2016). Energy exchange and evapotranspiration over irrigated seed maize agroecosystems in a desert-oasis region, northwest China. Agricultural and Forest Meteorology, 223, 48-59.

Zhu, W., Wu, B., Yan, N., Feng, X., \& Xing, Q. (2014). A method to estimate diurnal surface soil heat flux from MODIS data for a sparse vegetation and bare soil. Journal of Hydrology, 511, 139-150. 